\title{
Long-term follow-up of ipilimumab-induced hypophysitis, a common adverse event of the anti-CTLA-4 antibody in melanoma
}

\author{
Frédérique Albarel $\mathrm{I}^{1,2}$, Caroline Gaudy ${ }^{3}$, Frédéric Castinetti ${ }^{1,2}$, Tiphaine Carré ${ }^{3}$, \\ Isabelle Morange ${ }^{1,2}$, Bernard Conte-Devolx ${ }^{1,2}$, Jean-Jacques $\mathrm{Grob}^{3}$ and \\ Thierry Brue ${ }^{1,2}$ \\ ${ }^{1}$ Assistance Publique - Hôpitaux de Marseille (AP-HM), Hôpital Timone, Service d'Endocrinologie et Centre de \\ Référence des Maladies Rares d'Origine Hypophysaire DEFHY, 13385 Marseille Cedex 15, Marseille, France, \\ ${ }^{2}$ Aix-Marseille Université, CNRS, CRN2M-UMR7286, 13344 Marseille Cedex 15, Marseille, France and \\ ${ }^{3}$ Aix-Marseille Université, Assistance Publique - Hôpitaux de Marseille (AP-HM), Hôpital Timone, Service de \\ dermatologie, 13385 Marseille Cedex 15, Marseille, France
}

Correspondence should be addressed to T Brue

Email

thierry.brue@univ-amu.fr

\begin{abstract}
Objective: Few data are published on the long-term follow-up of ipilimumab-induced hypophysitis, a cytotoxic T-lymphocyte antigen 4 antibody. We characterized hypophysitis in terms of clinical signs, endocrinological profile, and imaging at diagnosis and during a long-term follow-up.

Design and patients: Fifteen patients, treated for malignant melanoma and who presented ipilimumab-induced hypophysitis, were observed between June 2006 and August 2012 in Timone Hospital, Marseille.

Methods: Symptoms, pituitary function, and pituitary imaging at diagnosis of hypophysitis and during the follow-up were recorded.

Results: Of 131 patients treated with ipilimumab or a placebo, 15 patients $(10 \mathrm{mg} / \mathrm{kg}$ in $11 / 15)$ presented with hypophysitis $(\geq 11.5 \%)$ at $9.5 \pm 5.9$ weeks (mean \pm s.D.) after treatment start, occurring in $66 \%$ after the third infusion. The main initial symptoms were headache $(n=13)$ and asthenia $(n=11)$. All patients but one had at least one hormonal defect: thyrotroph $(n=13)$, gonadotroph $(n=12)$, or corticotroph $(n=11)$ deficiencies. None had diabetes insipidus. Pituitary imaging showed a moderately enlarged gland in 12 patients. Clinical symptoms improved rapidly on high-dose glucocorticoids $(n=11)$ or physiological replacement doses $(n=4)$. At the end of follow-up (median 33.6 months, range 7-53.5), corticotroph deficiency remained in 13 patients, 11 recovered thyrotroph and ten gonadotroph functions. Pituitary imaging remained abnormal in 11 patients.

Conclusion: Ipilimumab-induced hypophysitis is a common side-effect with frequent hormonal deficiencies at diagnosis. Usually, hormonal deficiencies improved, except for corticotroph function. Patients receiving these immunomodulatory therapies should be closely monitored especially by systematic baseline hormone measurements after the third infusion and remain at a risk of adrenal insufficiency in the long-term.
\end{abstract}

\section{Introduction}

Autoimmune hypophysitis is a rare disease, with an estimated incidence of one in nine million people per year (1). It is characterized by cellular infiltration and inflammation of the pituitary gland. Hypophysitis is more frequent in late pregnancy and in the post-partum period. It can be primary or secondary to systemic disease, local lesions, or immunomodulatory drugs. It can affect only the anterior pituitary (adenohypophysitis, resulting in
(C) 2015 European Society of Endocrinology Printed in Great Britain
Published by Bioscientifica Ltd. 
variable pituitary defects), the infundibulum (infundibuloneurohypophysitis with diabetes insipidus), or the entire pituitary gland (pan-hypophysitis) $(2,3)$. Diagnosis is most often presumptive: because surgery is unnecessary, this makes pathological analysis impossible. Moreover, currently available anti-pituitary antibodies do not have enough diagnostic accuracy as no specific antigen has been identified in this pathology $(3,4,5)$. Diagnosis is thus based on the association between pituitary mass and tumor-related symptoms (headache and visual field defect), variable degrees of hypopituitarism, or hyper-prolactinemia (6).

A new etiology of hypophysitis has recently been described in association with a specific immunomodulatory therapy that uses human MABs against the cytotoxic T-lymphocyte antigen 4 (CTLA4 Ab). T-lymphocyte CTLA4 receptors enhance self-tolerance by downregulating the T-cell activation pathway, which could potentiate tumor development. By blocking the CTLA4 receptor, CTLA4 Ab promotes an immune response and antitumor activity $(7,8,9)$. The use of ipilimumab, a CTLA4 Ab, was approved in 2011 by the US Food and Drug Administration for the treatment of advanced malignant melanoma: two recent phase-III studies have reported improved overall survival in metastatic melanomas $(10,11)$. Anti-CTLA4 Ab treatment, with doses ranging from 0.3 to $10 \mathrm{mg} / \mathrm{kg}$, is currently being assessed in many clinical trials as a therapeutic agent for malignant melanoma, renal-cell carcinoma, prostate cancer, lung cancer, pancreatic adenocarcinoma, liver cancer, ovarian cancer, lymphoma, leukemia, and other hematological disorders and solid tumors (12). However, anti-CTLA4 Ab therapy is also responsible for increased autoimmunity $(7,8)$. The use of this drug is thus associated with multiple and variable immune-related adverse events (IRAEs), mainly concerning the gastro-intestinal tract, liver, skin, and endocrine system (hypophysitis, autoimmune thyroid disease, and primary adrenal insufficiency) $(13,14,15)$.

In a recent pooled analysis of 325 patients treated with four infusions of $10 \mathrm{mg} / \mathrm{kg}$ ipilimumab, IRAEs were observed in $72.3 \%$, with $25.2 \%$ of severe IRAEs (grade 3 or 4 ). Specific timing of occurrence was observed depending on tissue type: after 2-3 weeks for skin, later for gastrointestinal and hepatic IRAE, and $>9$ weeks for hypophysitis (13). An association between the occurrence of IRAEs and relapse-free survival and a favorable response to therapy and tumor regression is still debated $(16,17,18)$. A recent study has suggested a positive correlation between hypophysitis and survival using ipilimumab for metastatic melanoma (19).
Only a few cases of ipilimumab-induced hypophysitis have been described, mostly as case reports, although a few series have been published $(12,15,19,20,21,22)$. The largest studies have included, respectively, 13 and 17 patients (14 with hormonal data), but clinical, biological, and imaging data were often incomplete or partial, and/or the follow-up periods were short after initiation of ipilimumab $(18,19)$. As reported in a recent review (20), initial symptoms were usually related to tumor mass or hormone deficiencies, and rarely to visual disturbance or diabetes insipidus. Corticotroph and thyrotroph deficiencies were present in all cases, and gonadotroph deficiency was common in males. In these studies, the somatotroph axis and prolactin levels were rarely studied $(12,20,23)$. Magnetic-resonance images (MRIs) were variable, from normal to typical hypophysitis; in most cases, pituitary enlargement was modest and decreased with glucocorticoid treatment $(22,24)$. These data have been confirmed in a recent series that found no diabetes insipidus in 17 patients with ipilimumabinduced hypophysitis. In this study, a majority of patients presented with headache and with thyrotroph and gonadotroph deficiencies at diagnosis (only seven of the 14 patients with hormonal data had corticotroph deficiency), with mild to moderate diffuse pituitary enlargement evident in the MRIs (19). Of note, very few follow-up data are available, making it difficult to determine the endocrine outcomes of such patients.

Our study was aimed at analyzing the clinical, biological, and imaging characteristics, and the longterm follow-up outcomes of 15 patients who presented with autoimmune hypophysitis induced by ipilimumab (CTLA4 Ab), given at 3 or $10 \mathrm{mg} / \mathrm{kg}$, delivered for a malignant melanoma. These patients were followed at our center for a median of 33.6 months, range 7-53.5, enabling us to obtain long-term follow-up data.

\section{Patients and methods}

\section{Design and patients}

A total of 131 patients with a malignant melanoma were enrolled in this study from either ongoing trials or during temporary authorization for use (TAU). The study was conducted between June 2006 and August 2012 in the Department of Dermatology, La Timone Hospital (Marseille, France). Because several of these patients were included in trials that are still blinded, the real number of patients that received ipilimumab ranged from 87 to 131 : this included 62 patients with stage-IV metastatic 
melanoma who were treated with ipilimumab at a dose of $3 \mathrm{mg} / \mathrm{kg}$ (TAU); 25 patients with stage-IV metastatic melanoma who were treated with variable doses ranging from 0.3 to $10 \mathrm{mg} / \mathrm{kg}$; and an as-yet unknown (until unblinding) proportion of 44 patients with stage-III malignant melanoma (positive lymph nodes and no other evidence of metastatic disease spread) who received ipilimumab as an adjuvant therapy $(10 \mathrm{mg} / \mathrm{kg})$.

Written informed consent was obtained from all patients. Modalities of administration of ipilimumab depended on the stage of disease. Stage-IV patients received four infusions, with 3 weeks between each infusion, and a possibility of re-induction. In stage-III, the induction phase was similar (one treatment every 3 weeks, repeated four times), followed by a maintenance phase with an infusion every 3 months for up to 3 years.

Before starting treatment, all patients were initially evaluated for hormonal status. This included measurement of the following baseline hormone levels: free thyroxin $\left(\mathrm{T}_{4}\right)$, thyroid-stimulating hormone (TSH), cortisol, and adrenocorticotropic hormone (ACTH) and testosterone (for men). Data were first retrospectively analyzed until September 2010. After this date, when a diagnosis of hypophysitis was suspected, patients were systematically referred, in a prospective manner, to the same endocrinologist who collected the follow-up clinical, biological, and imaging data, and advised on hormone treatments.

A diagnosis of hypophysitis was presumptive, based on the association between clinical symptoms (related to tumor mass or hormone deficiencies) and hormonal abnormalities or radiological signs at pituitary MRI or computed tomography (CT) scan evaluation (6). As no patient was treated surgically, none had pathological confirmation of the diagnosis of hypophysitis.

\section{Clinical, hormonal, and imaging evaluation}

Patients received close and systematic monitoring: this included clinical and biological (TSH and free $\mathrm{T}_{4}$ level, and ACTH-cortisol and testosterone levels in males) data and a body CT scan during the treatment period and before and after each infusion of ipilimumab and then at least every 3 months.

When hypophysitis was clinically suspected, these patients were referred to the endocrinologist. All patients had an initial hormonal evaluation: TSH, tri-iodothyronine, $\mathrm{T}_{4}, 0800 \mathrm{~h}$. ACTH-cortisol, luteinizing hormone, follicle-stimulating hormone, testosterone/estradiol, prolactin, insulin-like growth factor 1 (IGF1), urinary volume, and plasma osmolality, and pituitary imaging (MRI or CT if contraindicated). Ophthalmologic evaluations, using Goldman's campimetry, were carried out in the ophthalmology department of our hospital at 3 months, and earlier if visual disturbance was suspected. Pituitary dysfunction led to substitutive hormonal treatment. High-dose glucocorticoids (at least $0.5 \mathrm{mg} / \mathrm{kg}$ methylprednisolone, prednisolone, or prednisone) were given when necessary and maintained for at least 15 days at maximal dose before a progressive decrease. The decrease in glucocorticoid dose occurred over one to several months, depending on clinical response, especially if other IRAEs were present. Substitutive therapy with hydrocortisone was introduced subsequently after discontinuation of other glucocorticoids. Patients had clinical (assessed by the endocrinologist), hormonal, and imaging follow-up investigations at 3 months, and then at least once yearly.

A deficiency of TSH was defined as a low plasma $\mathrm{T}_{4}$ level $(<12 \mathrm{pmol} / \mathrm{l})$ with a low or inappropriately normal TSH level. ACTH deficiency was diagnosed if there was a low cortisol level $(<200 \mathrm{nmol} / \mathrm{l})$ with low or inappropriately normal ACTH level at $0800 \mathrm{~h}$. An insulin-tolerance test was then performed if cortisol was found to be between 200 and $360 \mathrm{nmol} / 1$ or if there were clinical symptoms (see below) suggesting partial adrenal insufficiency. Gonadotroph deficiency was defined by low plasma sex steroids with inappropriate gonadotrophin levels (normal or low) and amenorrhea in non-menopausal women, or a lack of increase on gonadotrophins in menopausal women. Hyperprolactinemia was defined as a basal plasma prolactin level of $>25 \mathrm{ng} / \mathrm{ml}$, and prolactin was considered low when it was $<5 \mathrm{ng} / \mathrm{ml}$. Plasma IGF1 was determined in a RIA (Beckman Coulter-Immunotech, Marseille, France) and was standardized according to normal values for age, gender, and, if needed, pubertal status. Posterior pituitary function was assessed by clinical symptoms, as well as by measurement of urinary volume, plasma, and urinary osmolality.

At the 3-month evaluation, when possible, an insulintolerance test (insulin $0.1 \mathrm{UI} / \mathrm{kg}$ i.v.) was performed, and cortisol and growth hormone (GH) peaks were evaluated. The responses were considered adequate if the cortisol peak was $>550 \mathrm{nmol} / \mathrm{l}$ and the GH peak was $>3 \mu \mathrm{g} / \mathrm{l}$ (with a blood-glucose nadir of $<2.2 \mathrm{mmol} / \mathrm{l}$ ).

A pituitary MRI or CT was performed using sagittal, coronal, and axial sections. MRI sequences were spin-echo T1- and T2-weighted images, followed by post-gadolinium T1-weighted images. Pituitary imaging was performed at diagnosis, at 3 months evaluation, and then yearly when possible. 


\section{Statistical analyses}

Descriptive statistics with quantitative variables were expressed as their means \pm s.D. and, for follow-up, in median with ranges (minimum-maximum). Occurrences of IRAEs, and clinical, hormonal and imaging abnormalities, were expressed as absolute numbers and percentages.

\section{Results}

Because some patients are in ongoing randomized trials that are not yet unblinded, the actual incidence of hypophysitis could not be precisely assessed. Depending on the randomization rate, a maximum of 131 patients actually received ipilimumab; of these, 15 experienced hypophysitis, which resulted in a minimum estimated percentage of $11.5 \%$. Among these, two (minimum estimated percentage $2 / 62,3.2 \%$ ) were treated with ipilimumab at a dose of $3 \mathrm{mg} / \mathrm{kg}, 11$ (minimum estimated percentage $11 / 44,25 \%$ ) received $10 \mathrm{mg} / \mathrm{kg}$, and two (minimum estimated percentage $2 / 12,16.7 \%$ ) received 3 or $10 \mathrm{mg} / \mathrm{kg}$. All patients had a normal hormonal evaluation before beginning anti-CTLA4 Ab therapy.

\section{Patients' characteristics}

Mean age at diagnosis of hypophysitis was $55.5 \pm 11.2$ years; most were male patients (ten males and five females) (Table 1). Hypophysitis was diagnosed from February 1, 2010 until August 6, 2012. Patients received their first infusion of ipilimumab between September 30, 2009 and May 31, 2012. They presented the first symptoms of hypophysitis after an average of $9.5 \pm 5.9$ weeks; two patients (13.3\%) after the second infusion of ipilimumab, ten patients $(66.7 \%)$ after the third infusion, and three patients (20\%) after the fourth infusion.

\section{Initial evaluation}

At diagnosis, patients usually had non-specific complaints: moderate to severe headache $(n=13)$, asthenia and weakness $(n=11)$, decreased libido $(n=3)$, and dizziness $(n=2)$. None had visual disturbance, polyuria, or polydipsia.

Endocrine evaluation showed corticotroph deficiency in 11 patients (73.3\%), thyrotroph deficiency in 13 $(86.6 \%)$, and gonadotroph deficiency in 12 patients (85.7\%, one patient receiving contraceptive pills could not be evaluated) (Table 1). Two of eight patients had low IGF1 (patients 7 and 13), no insulin-tolerance test was
Table 1 Characteristics and evolution of patients who presented with autoimmune hypophysitis associated with ipilimumab.

\begin{tabular}{|c|c|c|c|}
\hline $\begin{array}{l}\text { Patient characteristics } \\
n=15\end{array}$ & & $\begin{array}{c}\text { At } \\
\text { diagnosis }\end{array}$ & $\begin{array}{l}\text { End of } \\
\text { follow- } \\
\text { up }\end{array}$ \\
\hline Age at diagnosis (years) & $55.5 \pm 11.2$ & & \\
\hline Gender ratio (men/women) & $2 / 1$ & & \\
\hline $\begin{array}{l}\text { Duration of follow-up, } \\
\text { median (months) }\end{array}$ & $33.6(7-53.5)$ & & \\
\hline $\begin{array}{l}\text { First symptoms after } \\
\text { ipilimumab treatment } \\
\text { (weeks) }\end{array}$ & $9.5 \pm 5.9$ & & \\
\hline \multicolumn{4}{|c|}{ Hormonal defects ( $n=$ patients/number of data) } \\
\hline Corticotroph & & $11 / 15$ & $13 / 15$ \\
\hline Thyrotroph & & $13 / 15$ & $2 / 15$ \\
\hline Gonadotroph & & $12 / 14$ & $2 / 15$ \\
\hline Somatotroph & & $2^{a} / 8$ & $1 \mathrm{~b} / 11$ \\
\hline Lactotroph & & $3 / 9$ & $1 / 11$ \\
\hline Diabetes insipidus & & 0 & 0 \\
\hline Hyperprolactinemia & & $1 / 9$ & $1 / 11$ \\
\hline \multicolumn{4}{|l|}{ Hormone replacement } \\
\hline Glucocorticoids & & $11 \% / 15$ & 13 \\
\hline Thyroxin & & 5 & 2 \\
\hline Sex hormones & & 0 & 1 \\
\hline $\begin{array}{l}\text { Imaging abnormalities }(n= \\
\text { patients/number of data) }\end{array}$ & & $12 / 14$ & $11 / 14$ \\
\hline
\end{tabular}

aLow IGF1.

${ }^{\mathrm{b}} \mathrm{An}$ insufficient GH peak in an insulin-tolerance test and low IGF1 (eight insulin-tolerance tests were performed).

'Seven high-doses and four replacement doses, and four patients with no defects received high-dose glucocorticoids for hypophysitis.

performed on $\mathrm{GH}$ in these patients at diagnosis. One had moderate hyperprolactinemia ( $32 \mathrm{ng} / \mathrm{ml}$, patient 8$)$, whereas $3 / 9$ had a low prolactin level $(<5 \mathrm{ng} / \mathrm{ml}$, patient 7,10 , and 13). No patient had diabetes insipidus (Tables 1 and 2).

Overall, one patient had normal pituitary function at diagnosis, one had an isolated pituitary deficiency (hypogonadotroph hypogonadism), whereas the remaining 13 patients had at least two pituitary deficiencies.

Eleven patients (seven with a corticotroph deficiency and four with normal corticotroph function) were then treated with high-dose glucocorticoids, while the remaining four patients (who all had a corticotroph deficiency) received substitutive glucocorticoid therapy. Five patients received $\mathrm{L}_{-} \mathrm{T}_{4}$ therapy. None received sex-steroid hormone treatment immediately after diagnosis.

All but one of the 15 patients underwent initial imaging of the pituitary (12 MRIs and two CTs) at, on average, $20 \pm 17.5$ days after diagnosis. Among these, 12 images were considered abnormal by the neuroradiologist (Fig. 1), with a moderately enlarged and homogeneously enhanced pituitary, a convex aspect of the gland, and 
Table 2 Patients who presented with ipilimumab-induced hypophysitis: at diagnosis.

\begin{tabular}{|c|c|c|c|}
\hline $\begin{array}{l}\text { Patient } \\
\text { (ipilimumab dose) }\end{array}$ & $\begin{array}{c}\text { Age at } \\
\text { diagnosis/ } \\
\text { gender }\end{array}$ & $\begin{array}{l}\text { Time/number } \\
\text { of infusions } \\
\text { to diagnosis } \\
\text { (weeks) }\end{array}$ & $\begin{array}{c}\text { Follow- } \\
\text { up } \\
\text { (months) }\end{array}$ \\
\hline $1(3 \mathrm{mg} / \mathrm{kg})$ & $45.8 / \mathrm{M}$ & $9.0 / 3$ & 11.4 \\
\hline $2(3 \mathrm{mg} / \mathrm{kg})$ & $60.9 / \mathrm{M}$ & $6.7 / 3$ & 22.1 \\
\hline $3(10 \mathrm{mg} / \mathrm{kg})$ & $80.3 / \mathrm{M}$ & $9.4 / 3$ & 37.5 \\
\hline $4(10 \mathrm{mg} / \mathrm{kg})$ & 43.8/M & $3.1 / 2$ & 33.6 \\
\hline $5(10 \mathrm{mg} / \mathrm{kg})$ & $47.8 / F$ & $9.0 / 3$ & 32.4 \\
\hline $6(10 \mathrm{mg} / \mathrm{kg})$ & $54.1 / \mathrm{M}$ & $5.7 / 3$ & 15.9 \\
\hline $7(10 \mathrm{mg} / \mathrm{kg})$ & 61.8/M & $28.1 / 4$ & 52.5 \\
\hline $8(10 \mathrm{mg} / \mathrm{kg})$ & $46.5 / F$ & $13.9 / 4$ & 47.4 \\
\hline $9(10 \mathrm{mg} / \mathrm{kg})$ & $52.1 / \mathrm{M}$ & $7.1 / 3$ & 49.6 \\
\hline $10(10$ mg/kg) & 39.8/M & $9.3 / 3$ & 43.1 \\
\hline $11(10$ mg/kg) & 67.7/M & $9.3 / 3$ & 27.5 \\
\hline $12(10 \mathrm{mg} / \mathrm{kg})$ & $50.5 / F$ & $9.9 / 4$ & 39.8 \\
\hline 13 (3 vs 10 mg/kg) & $59.0 / F$ & $7.0 / 3$ & 25.7 \\
\hline 14 (10 mg/kg) & 67.0/M & $6.0 / 2$ & 43.0 \\
\hline 15 (3 vs 10 mg/kg) & $60.7 / F$ & $9.6 / 3$ & 7.0 \\
\hline
\end{tabular}

\begin{tabular}{c}
$\begin{array}{c}\text { Symptoms } \\
\text { at } \\
\text { diagnosis }\end{array}$ \\
\hline$H+A$ \\
$H+A$ \\
$H+A$ \\
$H+A$ \\
$H$ \\
$H+A+D L$ \\
$H+A+D i$ \\
$H$ \\
$H+A+D L$ \\
$H$ \\
$H+A+D L+D i$ \\
$A$ \\
$H$ \\
$A$ \\
$H+A$ \\
\hline
\end{tabular}

\begin{tabular}{c}
\hline Corticotroph \\
deficiency (D) \\
\hline$Y$ \\
$N$ \\
$Y$ \\
$N$ \\
$Y$ \\
$Y$ \\
$Y$ \\
$Y$ \\
$N$ \\
$Y$ \\
$N$ \\
$Y$ \\
$Y$ \\
$Y$ \\
$Y$
\end{tabular}

\begin{tabular}{l} 
Treatment \\
\hline GC HD \\
GH HD \\
GC HD \\
GC HD \\
GC HD \\
GC HD \\
GC HD \\
GC \\
GC HD \\
GC HD \\
GC HD \\
GC \\
GC \\
GC HD \\
GC \\
\hline
\end{tabular}

\begin{tabular}{|c|}
\hline $\begin{array}{c}\text { Thyrotroph or } \\
\text { gonadotroph } \\
\text { deficiency } \\
\text { (treatment) }\end{array}$ \\
\hline $\begin{array}{c}T d+G \\
G\end{array}$ \\
\hline$\underset{N}{T d(T)}+G$ \\
\hline $\mathrm{Td}(\mathrm{T})$ \\
\hline$T d+G$ \\
\hline $\begin{array}{c}T d(T)+G \\
T d+G\end{array}$ \\
\hline$T d(T)+G$ \\
\hline$T d+G$ \\
\hline $\mathrm{Td}+\mathrm{G}$ \\
\hline $\mathrm{Td}+\mathrm{NA}$ \\
\hline$T d(T)+G$ \\
\hline $\mathrm{Td}+\mathrm{G}$ \\
\hline $\mathrm{Td}+\mathrm{G}$ \\
\hline
\end{tabular}

\begin{tabular}{c}
\hline $\begin{array}{c}\text { Imaging } \\
\text { (time to } \\
\text { diagnosis, days) }\end{array}$ \\
\hline EP (7) \\
EC (4) \\
NA \\
EC (58) \\
EP (14) \\
EC (24) \\
EC (54) \\
EC (28) \\
EP+EC (31) \\
EP+EC+EPS (18) \\
EP+EC (6) \\
CT: EP+EC+EPS (9) \\
EP+EC (13) \\
EC (6) \\
TDM: EC+EPS (8) \\
\hline
\end{tabular}

$M$, male; F, female. Symptoms: $H$, headache; $A$, asthenia; DL, decreased libido; Di, dizziness; $Y$, yes; N, no; GC, glucocorticoids; HD, high dose; Td, thyrotroph deficiency; T, L-thyroxin; G, gonadotroph deficiency; NA, not available. Imaging: EP, enhanced pituitary; EC, enhanced contrast; EPS, enhanced pituitary stalk; CT, computed tomography.

enlargement of the pituitary stalk or the infundibulum. Two patients had normal pituitary images at MRI.

\section{Follow-up period}

The median length of follow-up was 33.6 months, range 7-53.5 months after hypophysitis, or 34.5 months, range 9.3-60 months after the initiation of ipilimumab. Five patients died from progressive metastatic melanoma. Eleven patients presented with IRAEs; the most frequent were enterocolitis and diarrhea $(n=6)$, and rash or other adverse autoimmune skin-related events $(n=5)$. No other immunerelated endocrine disease was observed in these patients, and eight were negative for thyroid antibodies. By the end of the follow-up period, seven patients had stopped ipilimumab due to progression of disease, five because of adverse events (discontinuation because of pituitary side-effects for two patients), and the three others were still ongoing 'postipilimumab follow-up without treatment'.

All patients had rapid improvement of clinical symptoms in the first month after beginning glucocorticoid therapy. Two patients developed corticotroph deficiency at the end of glucocorticoid treatment. None of the 13 patients showed recovery of corticotroph function at the end of the follow-up period. Eleven patients recovered normal thyrotroph and ten patients recovered normal gonadotroph functions. One patient had IGF1 (patient 7) and two patients' prolactin levels (patient 7 and 10) normalized during the follow-up.
Overall, at the last follow-up, 13 patients had corticotroph deficiency (all treated with physiological replacement doses of hydrocortisone), two had thyrotroph deficiency (both received substitutive treatments), two had gonadotroph deficiency (one man received testosterone, introduced during follow-up), and one patient had a somatotroph deficiency (patient 13; on eight insulintolerance test). One patient still had hyper-prolactinemia (patient 8) and one of 11 patients had a low prolactin level (patient 13). There was still no occurrence of diabetes insipidus (Tables 1 and 3 ).

Fourteen patients had early re-evaluation of pituitary images during the follow-up period: 12 MRIs and two CTs, at a mean time of $7.2 \pm 4.3$ months. Eleven of these showed abnormalities (Fig. 1), including decreased pituitary volume, a concave pituitary aspect or an empty sella turcica. The images became normalized in three patients during the follow-up (all three had received high-dose glucocorticoids as the initial treatment).

\section{Discussion}

This study is the first large series to conduct analyses, during a more than 2.5-year median follow-up period, on the clinical, hormonal, and imaging statuses of patients treated with ipilimumab (CTLA4 $\mathrm{Ab}$ ) for malignant melanoma and who presented with autoimmune hypophysitis. Indeed, most publications on ipilimumab-induced hypophysitis are usually case reports 
Table 3 Patients who presented with ipilimumab-induced hypophysitis: the follow-up.

\begin{tabular}{|c|c|c|c|c|c|c|}
\hline & $\begin{array}{c}\text { Corticotroph } \\
\text { deficiency }\end{array}$ & $\begin{array}{c}\text { Thyrotroph deficiency } \\
\text { (treatment or recovery, } \\
\text { months) }\end{array}$ & $\begin{array}{c}\text { Gonadotroph } \\
\text { defiency (treatment } \\
\text { or recovery, months) }\end{array}$ & $\begin{array}{l}\text { Follow-up } \\
\text { Imaging (D) }\end{array}$ & Other AEs, death & $\begin{array}{l}\text { Ipilimumab } \\
\text { (reason) }\end{array}$ \\
\hline 1 & $\mathrm{Y}$ & $N(6)$ & $\mathrm{N}(0.5)$ & No & EC, death & $N(P)$ \\
\hline 2 & $\mathrm{~N}$ & $N(N D)$ & $N(4)$ & EST & $\mathrm{S}$ & $N(P)$ \\
\hline 3 & $\mathrm{Y}$ & $\mathrm{N}(\mathrm{NA})$ & $\mathrm{N}(11)$ & EST & & $N(P)$ \\
\hline 4 & $\mathrm{~N}$ & $N(N D)$ & $\mathrm{N}(\mathrm{ND})$ & No & & $N(P)$ \\
\hline 5 & $\mathrm{Y}$ & N (24) & $N(N D)$ & DPV & $\mathrm{D} / \mathrm{EC}$, s, death & $N(P)$ \\
\hline 6 & $\mathrm{Y}$ & $N(1)$ & $N(0.5)$ & NA & & $N(A E)$ \\
\hline 7 & $\mathrm{Y}$ & $Y(T)$ & Y (Te) & CT: DPV, CPA & $\mathrm{S}$ & FU \\
\hline 8 & $\mathrm{Y}$ & $\mathrm{N}(5)$ & $N(5)$ & DPV & $\mathrm{S}$ & FU \\
\hline 9 & $\mathrm{Y}$ & $\mathrm{N}(20)$ & $\mathrm{N}(11)$ & DPV & $\mathrm{EC}, \mathrm{R}$ & $N(A E)$ \\
\hline 10 & $\mathrm{Y}$ & $N(6)$ & $N(6)$ & No & $\mathrm{EC}$ & $N(A E)$ \\
\hline 11 & $\mathrm{Y}$ & $\mathrm{N}(2.5)$ & $N(1.5)$ & CPA & $N, D, E C, R$, death & $N(A E)$ \\
\hline 12 & $\mathrm{Y}$ & N (3) & N (NA) & CPA & & FU \\
\hline 13 & $\mathrm{Y}$ & $Y(T)$ & $\mathrm{Y}$ & CPA & S, death & $N(P)$ \\
\hline 14 & $\mathrm{Y}$ & $\mathrm{N}(0.5)$ & $\mathrm{N}(3.5)$ & CPA & $\mathrm{H}$ & $N(A E)$ \\
\hline 15 & $\mathrm{Y}$ & $\mathrm{N}(0.5)$ & $N(2)$ & CT: DPV & $\mathrm{EC}, \mathrm{S}$, death & $N(P)$ \\
\hline
\end{tabular}

Y, yes; N, no; T, L-thyroxin; ND, no defect; NA, not available; Te, testosterone; Follow-up imaging: CT, computed tomography; EST, empty sella turcica; DPV, decreased pituitary volume; CPA, concave pituitary aspect; No, normal; AE, adverse event; EC, enterocolitis; S, skin; D, diarrhea; R, immune-related renal failure; $H$, hepatitis; P, progression; $A E$, adverse event; FU, follow-up without treatment.

$(12,15,20,21,22)$; larger series have usually addressed efficacy or CTLA4 Ab-induced IRAEs without focusing on hypophysitis $(18,21,25)$ or have too short follow-up periods to assess long-term evolution (19).

Our aim was to deduce, from these detailed data, the most appropriate monitoring method and follow-up for such patients, to provide relevant and informed advice.

In our study, the prevalence of hypophysitis in patients receiving ipilimumab was significant, although this could not be assessed precisely due to the ongoing blinding of several cases in our series. The lowest estimation of its incidence, based on the hypothesis that all still unblinded cases had received ipilimumab, was $11.5 \%$ (15 cases in 131 patients), with a $3 \%$ incidence (two cases in 62 patients) with $3 \mathrm{mg} / \mathrm{kg}$, and a $25 \%$ incidence (11 cases in 44 patients) in the group of patients that received ipilimumab at $10 \mathrm{mg} / \mathrm{kg}$, which is greater than previously reported. Indeed, the reported frequency of hypophysitis in the literature ranges from 0 to $17 \%$, depending on dose and study $(18,19,21,23,25,26)$. Thus, this IRAE seems to be dose dependent. The relationship between dose of ipilimumab and IRAEs is common, and seems also to be correlated with the antitumor response $(13,16,17,18)$. This dose-dependency has already been pointed out by Maker et al. (25) who found that a majority of patients who experience hypophysitis received a higher dose of ipilimumab (i.e. $9 \mathrm{mg} / \mathrm{kg}$ ).

The higher prevalence of hypophysitis in our study could, in part, be related to the ongoing increased experience of clinicians, who are nowadays more vigilant regarding the symptoms of this potentially lifethreatening IRAE; thus, systematic hormonal monitoring is practiced in our center.

In our study, patients' clinical presentations are atypical for hypophysitis. Autoimmune lymphocytic hypophysitis is reported to be more commonly observed in females (six women compared with one man), with a strong association with pregnancy, and a predominant occurrence in patients aged in their $30 \mathrm{~s}$ for females and in their early $40 \mathrm{~s}$ for males $(5,27)$. In contrast, in this study, the gender ratio favored men (two men: one woman); a male preponderance has been also noted in other studies $(19,28)$. Our patients were also older, with a mean age of 55.2 years at diagnosis. Moreover, even if the initial symptoms, although not specific, were reminiscent of that observed in other forms of hypophysitis (headache, asthenia...), the symptoms we observed related to mass effect were moderate: there was no visual disturbance and so no surgical decompression was necessary in our patients. Our patients presented with pituitary deficiencies, which usually affected several hormones (13/15), especially thyrotroph (86.6\%), gonadotroph (85.7\%), and corticotroph deficiencies $(73.3 \%)$, with only one case of hyperprolactinemia (11.1\%) and no cases of diabetes insipidus.

In lymphocytic hypophysitis, the most commonly described defect affects the corticotroph axis (32\%), and 18 and $31 \%$ of patients present with hyperprolactinemia and diabetes insipidus respectively (6). Note that, in our study, at diagnosis of hypophysitis, one patient did not 

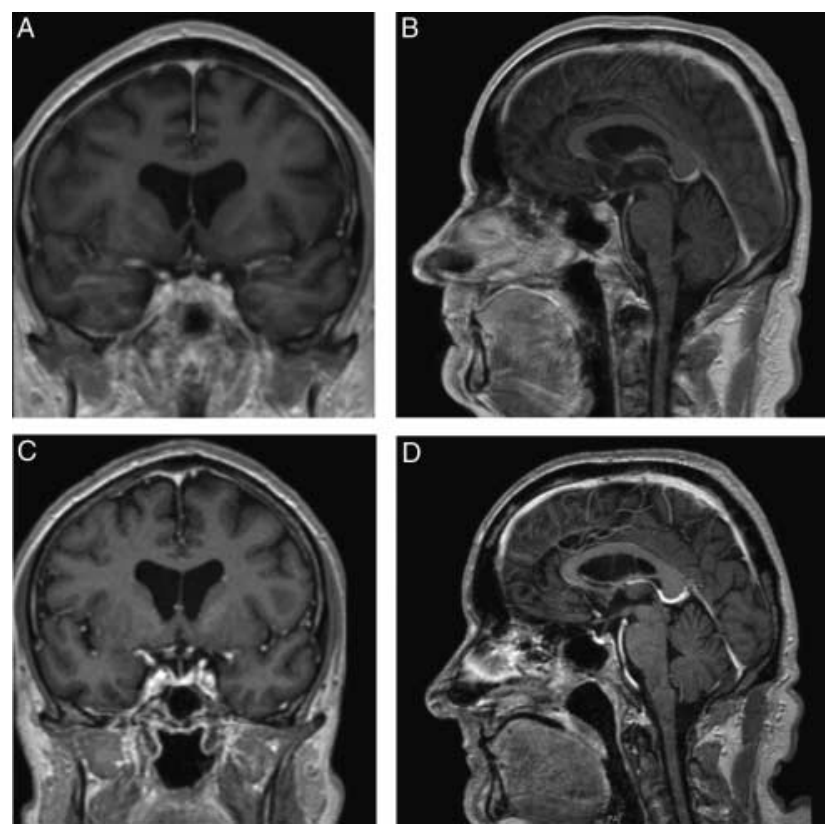

\section{Figure 1}

Pituitary MRI of a patient presenting with hypophysitis associated with ipilimumab. Pituitary MRI post-gadolinium T1-weighted images. (A) Coronal plane and (B) sagittal plane: at diagnosis, a pituitary gland with moderate enlargement and global-contrast enhancement, with a $17 \times 8 \times 10 \mathrm{~mm}$ size. (C) Coronal plane and (D) sagittal plane: during the follow-up period, at 7 months, there was an important decrease in pituitary volume, with a concave aspect of the gland.

have any pituitary defect and two had normal imaging. Such particular features make ipilimumab-induced hypophysitis a special entity, which has different characteristics at diagnosis and that specialists should be aware of. Nevertheless, regarding its evolution, it seems that it is not too different from the natural history of previously described autoimmune hypophysitis, with rapid improvement in clinical symptoms and that required ongoing hormone replacement in all but two patients by the end of the follow-up (13.3\%), and shrinkage of the tumor mass at imaging re-evaluation with normalization (3/14) or a decrease in pituitary volume (11/14) (5). This atypical hormonal presentation could, in part, be explained by the recent findings of Iwama et al. (29) who found that, in seven patients with hypophysitis and treated with ipilimumab, antibodies recognizing predominantly TSH-secreting cells (7/7) and also follicle-stimulating hormone- (5/7) and ACTH- (3/7) secreting cells appeared. In the same study, the expression of CTLA4 in

TSH- and PRL-secreting cells has been detected in the pituitary gland.

Our study has improved the description of the kinetics of hypophysitis after starting ipilimumab therapy. Indeed, most of our patients (10/15) presented with their first symptoms after the third infusion, at a mean time of 9.5 weeks after starting treatment; this corroborates with a recent analysis of 325 patients who were treated with $10 \mathrm{mg} / \mathrm{kg}$ of ipilimumab, where it took an average of 9 weeks before the onset of endocrine adverse events (mainly hypophysitis, in 3\% of patients, considered grade 3 or 4 IRAEs) (13). Also, the study by Min et al. (24) has reported a 9.4 week period before the onset of hypophysitis in eight patients who received $10 \mathrm{mg} / \mathrm{kg}$ of ipilimumab. These observations indicate that closer follow-up is needed during this period, which includes intensification of clinical and biological monitoring, and also imaging when hypophysitis is suspected. Our study also confirms the moderate degree of pituitary enlargement that occurred in hypophysitis associated with ipilimumab. However, despite the lack of visual disturbance in our series, two patients have been reported in the literature (20). Our study confirms that, in this setting, the involvement of the posterior pituitary is extremely rare, with only one case of diabetes insipidus described in the literature (11).

One of the crucial points with IRAEs that develop in association with ipilimumab, especially hypophysitis, is the attitude regarding treatment: should high-dose glucocorticoids be systematically administrated and should ipilimumab be stopped after the occurrence of hypophysitis? Different studies have not shown any deleterious effects of high-dose glucocorticoid therapy in cases of IRAEs associated with ipilimumab antitumor responses, and the duration of tumor response does not seem to be affected by this treatment $(18,23,30)$. Moreover, in our study, as in another analysis (23), high-dose glucocorticoids did not seem to change the natural history of hypophysitis, especially concerning life-threatening corticotroph function: patients who had a corticotroph defect at diagnosis still had this defect at the end of the follow-up period, irrespective of the type of glucocorticoid treatment, be it high-dose or a physiological replacement dose (23). All four patients who did not have a corticotroph defect at diagnosis in our study had received high-dose glucocorticoids: of these, two had a corticotroph defect at the end of the follow-up and two did not. Interestingly, the three patients who had normalized imaging by the end of our study had received high-dose glucocorticoids. Because of the still limited experience, it is difficult to 
deduce strict recommendations. However, in a recent study, Lammert et al. (31) have observed complications in five out of seven patients (four who needed to be hospitalized) after administration of high-dose corticosteroids for ipilimumab-induced hypophysitis, and partial or complete hypopituitarism remained in all patients. Thus, we suggest that high-dose glucocorticoids are proposed for patients with ipililumab-induced hypophysitis who have serious mass-effect-related symptoms, such as severe headache, visual-field disturbance, or simultaneously presence of other IRAEs. Physiological replacement doses should be considered for others with corticotroph deficiency because pharmacologic glucocorticoid therapy was not clearly associated with improved outcomes in such patients. Concerning interrupting CTLA4 Ab treatment, most authors agree that the benefits of ipilimumab, regarding survival in the context of a potentially fatal malignancy, greatly outweigh the risks of continuing therapy using an appropriate substitutive treatment $(13,20,32,33)$. We believe that such patients should not have ipilimumab treatment interrupted after adapted management of hypophysitis; most of our patients continued their ipilimumab treatment without recurrence of any clinical symptoms. However, the discussion about the risks-benefits would be different in an anti-CTLA4 adjuvant setting, and the decision regarding treatment should be made after the patient has been fully informed of the risk of hypophysitis and corticotroph defect that usually persists: in our study there were no recoveries and, in the literature, only two recoveries have been reported $(18,19)$. Noteworthy in a recent study, the development of hypophysitis has been associated with a better outcome in patients with metastatic melanoma (19). Unfortunately, it is impossible to do so in our study, because several patients are included in clinical trials that are still blinded. Furthermore, a majority of the patients who presented hypophysitis in our study received $10 \mathrm{mg} / \mathrm{kg}$ ipilimumab as an adjuvant treatment for melanoma with positive lymph nodes and no other evidence of metastatic disease spread (stage-III malignant melanoma). In these patients with less severe disease than metastatic melanoma, two died during follow-up, so a longer follow-up would be necessary to assess survival benefit.

This study was conducted in a single center, which may represent both a strength in terms of homogeneity of data, but also a limitation in terms of recruitment and management choice. Before a referent endocrinologist became systematically involved in September 2010, the management of such cases had been relatively heterogeneous and initial evaluation was sometimes incomplete, which explains the missing values in our analyses. Moreover, until September 2010, patients had received high-dose glucocorticoids regardless of the clinical symptoms, and the cause of the corticotroph defects in these patients could be questioned: did they occur secondary to hypophysitis or to the high-dose glucocorticoid treatment? Evolution should permit us to answer this question. It is noteworthy that, in our study, diagnosis of hypophysitis was presumptive (clinical symptoms associated with hormonal or imaging abnormalities (6)), but no patient had any surgical indications (persistent headache, severe visual disturbance...), as pituitary enlargement is usually only moderate in this type of hypophysitis. Indeed, no previous study has reported anatomo-pathological analysis until now (19). Moreover, we did not perform a systematic pituitary MRI in all ipilimumab-treated patients: thus, it is possible that we underestimated the prevalence of ipilimumab-induced hypophysitis. Indeed, some authors have reported that progressive pituitary enlargement can be an early and sensitive tool in such diagnosis (19). Although routine MRIs cannot be recommended, nor can 18-FDG PET-CTs, which seems to be also an interesting tool for the early detection of hypophysitis associated with ipilimumab (34), these methods could be considered after the third injection of ipilimumab.

Overall, it should be kept in mind that diagnosis of hypophysitis after CTLA4 Ab therapy is, most of the time, presumptive and explorations during the follow-up period need to be systematic and frequent. It should include clinical, biological, and sometimes imaging, with particular attention given after the third infusion of ipilimumab. This need for close monitoring is all the more justified as the prevalence of hypophysitis associated with ipilimumab seems to be higher than was initially presumed, especially when given at a dose of $10 \mathrm{mg} / \mathrm{kg}$ : at least one in four patients presented with hypophysitis at this dose. Thyrotroph, gonadotroph, and corticotroph functions seem to be the most affected, with thyrotroph and gonadotroph functions usually recovering during follow-up. However, particular attention needs to be paid to corticotroph function, which has a possible delayed onset and may not recover, as in our study, for almost 3 years: thus, prolonged treatment is required and the patient needs to receive appropriate education regarding this long-term medication, with a long-term multi-disciplinary follow-up.

In the future, with the increased number of clinical trials on CTLA4 $\mathrm{Ab}$ and the development of new 
immunomodulatory drugs, the physicians in charge of these patients should be aware and updated guidelines should be elaborated and disseminated. Interestingly, it seems that hypophysitis is much more frequently associated with ipilimumab treatment than with other immunomodulatory drugs (hypophysitis $<1 \%$ with nivolumab, immunomodulatory drug evaluated in various type of cancer, Ab against programed death 1, inhibitor receptor expressed by activated $\mathrm{T}$ cells) $(35,36)$. Furthermore, new research on pituitary immunity and the ongoing development of sensible and specific antibodies should help us to increase diagnostic accuracy and to monitor this pathology $(29,37)$.

\section{Declaration of interest}

The authors declare that there is no conflict of interest that could be perceived as prejudicing the impartiality of the research reported.

\section{Funding}

This work was supported by the 'Association pour le Développement de la Recherche Médicale au Centre Hospitalier Universitaire de Marseille' (ADEREM).

\section{References}

1 Buxton N \& Robertson I. Lymphocytic and granulocytic hypophysitis: a single centre experience. British Journal of Neurosurgery $2001 \mathbf{1 5}$ 242-245. Discussion 245-246. (doi:10.1080/02688690120057664)

2 Laws ER, Vance ML \& Jane JA Jr. Hypophysitis. Pituitary 20069 331-333. (doi:10.1007/s11102-006-0415-6)

3 Carmichael JD. Update on the diagnosis and management of hypophysitis. Current Opinion in Endocrinology, Diabetes, and Obesity 201219 314-321. (doi:10.1097/MED.0b013e32835430ed)

4 Glezer A \& Bronstein MD. Pituitary autoimmune disease: nuances in clinical presentation. Endocrine 201242 74-79. (doi:10.1007/ s12020-012-9654-7)

5 Falorni A, Minarelli V, Bartoloni E, Alunno A \& Gerli R. Diagnosis and classification of autoimmune hypophysitis. Autoimmunity Reviews 2014 13 412-416. (doi:10.1016/j.autrev.2014.01.021)

6 Caturegli P, Lupi I, Landek-Salgado M, Kimura H \& Rose NR. Pituitary autoimmunity: 30 years later. Autoimmunity Reviews 20087 631-637. (doi:10.1016/j.autrev.2008.04.016)

7 Maker AV, Attia P \& Rosenberg SA. Analysis of the cellular mechanism of antitumor responses and autoimmunity in patients treated with CTLA-4 blockade. Journal of Immunology 2005175 7746-7754. (doi:10.4049/jimmunol.175.11.7746)

8 Tivol EA, Borriello F, Schweitzer AN, Lynch WP, Bluestone JA \& Sharpe AH. Loss of CTLA-4 leads to massive lymphoproliferation and fatal multiorgan tissue destruction, revealing a critical negative regulatory role of CTLA-4. Immunity 19953 541-547. (doi:10.1016/ 1074-7613(95)90125-6)

9 Chambers CA, Kuhns MS, Egen JG \& Allison JP. CTLA-4-mediated inhibition in regulation of $\mathrm{T}$ cell responses: mechanisms and manipulation in tumor immunotherapy. Annual Review of Immunology 200119 565-594. (doi:10.1146/annurev.immunol.19.1.565)
10 Hodi FS, O'Day SJ, McDermott DF, Weber RW, Sosman JA, Haanen JB, Gonzalez R, Robert C, Schadendorf D, Hassel JC et al. Improved survival with ipilimumab in patients with metastatic melanoma. New England Journal of Medicine 2010363 711-723. (doi:10.1056/ NEJMoa1003466)

11 Robert C, Thomas L, Bondarenko I, O'Day S, Weber J, Garbe C, Lebbe C, Baurain JF, Testori A, Grob JJ et al. Ipilimumab plus dacarbazine for previously untreated metastatic melanoma. New England Journal of Medicine 2011364 2517-2526. (doi:10.1056/NEJMoa1104621)

12 Dillard T, Yedinak CG, Alumkal J \& Fleseriu M. Anti-CTLA-4 antibody therapy associated autoimmune hypophysitis: serious immune related adverse events across a spectrum of cancer subtypes. Pituitary 201013 29-38. (doi:10.1007/s11102-009-0193-z)

13 Weber JS, Kähler KC \& Hauschild A. Management of immune-related adverse events and kinetics of response with ipilimumab. Journal of Clinical Oncology 201230 2691-2697. (doi:10.1200/JCO.2012.41.6750)

14 Maker AV, Phan GQ, Attia P, Yang JC, Sherry RM, Topalian SL, Kammula US, Royal RE, Haworth LR, Levy C et al. Tumor regression and autoimmunity in patients treated with cytotoxic T lymphocyteassociated antigen 4 blockade and interleukin 2: a phase I/II study. Annals of Surgical Oncology 200512 1005-1016. (doi:10.1245/ASO.2005. 03.536)

15 Phan GQ, Yang JC, Sherry RM, Hwu P, Topalian SL, Schwartzentruber DJ, Restifo NP, Haworth LR, Seipp CA, Freezer LJ et al. Cancer regression and autoimmunity induced by cytotoxic $\mathrm{T}$ lymphocyte-associated antigen 4 blockade in patients with metastatic melanoma. PNAS 2003100 8372-8377. (doi:10.1073/pnas. 1533209100)

16 Attia P, Phan GQ, Maker AV, Robinson MR, Quezado MM, Yang JC, Sherry RM, Topalian SL, Kammula US, Royal RE et al. Autoimmunity correlates with tumor regression in patients with metastatic melanoma treated with anti-cytotoxic T-lymphocyte antigen-4. Journal of Clinical Oncology 200523 6043-6053. (doi:10.1200/JCO.2005.06.205)

17 O'Day SJ, Hamid O \& Urba WJ. Targeting cytotoxic T-lymphocyte antigen-4 (CTLA-4): a novel strategy for the treatment of melanoma and other malignancies. Cancer 2007110 2614-2627. (doi:10.1002/ cncr.23086)

18 Downey SG, Klapper JA, Smith FO, Yang JC, Sherry RM, Royal RE, Kammula US, Hughes MS, Allen TE, Levy CL et al. Prognostic factors related to clinical response in patients with metastatic melanoma treated by CTL-associated antigen-4 blockade. Clinical Cancer Research 200713 6681-6688. (doi:10.1158/1078-0432.CCR-07-0187)

19 Faje AT, Sullivan R, Lawrence D, Tritos NA, Fadden R, Klibanski A \& Nachtigall L. Ipilimumab-induced hypophysitis: a detailed longitudinal analysis in a large cohort of patients with metastatic melanoma. Journal of Clinical Endocrinology and Metabolism 201499 4078-4085. (doi:10.1210/jc.2014-2306)

20 Juszczak A, Gupta A, Karavitaki N, Middleton MR \& Grossman AB. Ipilimumab: a novel immunomodulating therapy causing autoimmune hypophysitis: a case report and review. European Journal of Endocrinology 2012167 1-5. (doi:10.1530/EJE-12-0167)

21 Yang JC, Hughes M, Kammula U, Royal R, Sherry RM, Topalian SL, Suri KB, Levy C, Allen T, Mavroukakis S et al. Ipilimumab (anti-CTLA4 antibody) causes regression of metastatic renal cell cancer associated with enteritis and hypophysitis. Journal of Immunotherapy 200730 825-830. (doi:10.1097/CJI.0b013e318156e47e)

22 Carpenter KJ, Murtagh RD, Lilienfeld H, Weber J \& Murtagh FR. Ipilimumab-induced hypophysitis: MR imaging findings. American Journal of Neuroradiology 200930 1751-1753. (doi:10.3174/ajnr.A1623)

23 Blansfield JA, Beck KE, Tran K, Yang JC, Hughes MS, Kammula US, Royal RE, Topalian SL, Haworth LR, Levy C et al. Cytotoxic T-lymphocyte-associated antigen-4 blockage can induce autoimmune hypophysitis in patients with metastatic melanoma and renal cancer. Journal of Immunotherapy 200528 593-598. (doi:10.1097/01.cji. 0000178913.41256.06) 
24 Min L, Vaidya A \& Becker C. Association of ipilimumab therapy for advanced melanoma with secondary adrenal insufficiency: a case series. Endocrine Practice 201218 351-355. (doi:10.4158/EP11273.OR)

25 Maker AV, Yang JC, Sherry RM, Topalian SL, Kammula US, Royal RE, Hughes M, Yellin MJ, Haworth LR, Levy C et al. Intrapatient dose escalation of anti-CTLA-4 antibody in patients with metastatic melanoma. Journal of Immunotherapy 200629 455-463. (doi:10.1097/ 01.cji.0000208259.73167.58)

26 Weber JS, O'Day S, Urba W, Powderly J, Nichol G, Yellin M, Snively J \& Hersh E. Phase I/II study of ipilimumab for patients with metastatic melanoma. Journal of Clinical Oncology 200826 5950-5956. (doi:10.1200/JCO.2008.16.1927)

27 Caturegli P, Newschaffer C, Olivi A, Pomper MG, Burger PC \& Rose NR. Autoimmune hypophysitis. Endocrine Reviews 200526 599-614. (doi:10.1210/er.2004-0011)

28 Corsello SM, Barnabei A, Marchetti P, De Vecchis L, Salvatori R \& Torino F. Endocrine side effects induced by immune checkpoint inhibitors. Journal of Clinical Endocrinology and Metabolism 201398 1361-1375. (doi:10.1210/jc.2012-4075)

29 Iwama S, De Remigis A, Callahan MK, Slovin SF, WolchokJD \& Caturegli P. Pituitary expression of CTLA-4 mediates hypophysitis secondary to administration of CTLA-4 blocking antibody. Science Translational Medicine 20146 230ra45. (doi:10.1126/scitranslmed.3008002)

30 Weber J. Review: anti-CTLA-4 antibody ipilimumab: case studies of clinical response and immune-related adverse events. Oncologist 2007 12 864-872. (doi:10.1634/theoncologist.12-7-864)

31 Lammert A, Schneider HJ, Bergmann T, Benck U, Krämer BK, Gärtner R, Metzner C, Schöfl C \& Berking C. Hypophysitis caused by ipilimumab in cancer patients: hormone replacement or immunosuppressive therapy. Experimental and Clinical Endocrinology \& Diabetes 2013121 581-587. (doi:10.1055/s-0033-1355337)

32 Torino F, Barnabei A, De Vecchis L, Salvatori R \& Corsello SM. Hypophysitis induced by monoclonal antibodies to cytotoxic $\mathrm{T}$ lymphocyte antigen 4 : challenges from a new cause of a rare disease. Oncologist 201217 525-535. (doi:10.1634/theoncologist.2011-0404)

33 Boasberg P, Hamid O \& O'Day S. Ipilimumab: unleashing the power of the immune system through CTLA-4 blockade. Seminars in Oncology 201037 440-449. (doi:10.1053/j.seminoncol.2010.09.004)

34 Van der Hiel B, Blank CU, Haanen JB \& Stokkel MP. Detection of early onset of hypophysitis by (18)F-FDG PET-CT in a patient with advanced stage melanoma treated with ipilimumab. Clinical Nuclear Medicine 201338 182-184. (doi:10.1097/RLU.0b013e3182639765)

35 Torino F, Barnabei A, Paragliola RM, Marchetti P, Salvatori R \& Corsello SM. Endocrine side-effects of anti-cancer drugs: mAbs and pituitary dysfunction: clinical evidence and pathogenic hypotheses. European Journal of Endocrinology 2013169 R153-R164. (doi:10.1530/ EJE-13-0434)

36 Topalian SL, Hodi FS, Brahmer JR, Gettinger SN, Smith DC, McDermott DF, Powderly JD, Carvajal RD, Sosman JA, Atkins MB et al. Safety, activity, and immune correlates of anti-PD-1 antibody in cancer. New England Journal of Medicine 2012366 2443-2454. (doi:10.1056/ NEJMoa1200690)

37 Ricciuti A, De Remigis A, Landek-Salgado MA, De Vincentiis L, Guaraldi F, Lupi I, Iwama S, Wand GS, Salvatori R \& Caturegli P. Detection of pituitary antibodies by immunofluorescence: approach and results in patients with pituitary diseases. Journal of Clinical Endocrinology and Metabolism 201499 1758-1766. (doi:10.1210/ jc.2014-1049)

Received 6 October 2014

Revised version received 18 November 2014

Accepted 21 November 2014 